\title{
A note on managerial delegation with asymmetric and convex costs
}

Second revised version: July 14, 2015

\begin{abstract}
In this note we investigate if the standard result by the managerial delegation literature, that the sub-game perfect Nash equilibrium is not Pareto-optimal from the firms' viewpoint, still applies when asymmetric and convex costs are introduced into the analysis. In such a framework, the managerial delegation choice still represents a sub-game Nash perfect equilibrium, but the more efficient firm may obtain higher profits provided that the degree of cost asymmetry between firms is sufficiently large.
\end{abstract}

Keywords: managerial delegation, cost asymmetry, increasing marginal costs JEL codes: J51, L13, L21

\footnotetext{
* This version was much improved by the comments and suggestions of two anonymous referees. Usual disclaimers apply.
} 


\section{Introduction}

A well-known tenet of the managerial delegation literature (Vickers 1985; Fershtman 1985; Fershtman and Judd 1987; Sklivas 1987) is that, when firms compete in quantities, the sub-game perfect Nash equilibrium (SPNE), which implies that both firms delegate output decisions to their managers, is not Pareto-optimal from the firms' viewpoint, i.e. each firm's profit would be higher if they chose together not to delegate. While this literature typically assumes linear costs, in this note we introduce into the analysis the presence of increasing marginal costs, as well as cost differences among firms.

Several reasons have been provided in the literature for the existence of cost differences among firms, including efficiency of closing (Baden-Fuller 1989), learning-by-doing (Jovanovic and Lach 1989), monitoring technology (Shapiro and Stiglitz 1984), management skills (Holmes and Schmitz 1995), know-how (Jovanovic and McDonald 1994), scale economies (Ghemawat and Nalebuff 1985), and talent (Frank 1988). Moreover, different strands of the Industrial Organization literature have also analyzed how the presence of increasing marginal costs affects several features of industry, such as the profitability of a merger (Perry and Porter 1985; Heywood and McGinty 2007) or market outcomes in non-pure oligopoly frameworks (e.g., White 1996, in a mixed oligopoly). ${ }^{1}$ However, their effects on the equilibrium outcome in a managerial delegation game have not been investigated and we believe this is relevant to the concerns of management strategy and industrial organization.

To the best of our knowledge, few works deal specifically with the issue of this paper. Bhattacharjee and Pal (2013) show that, in the presence of strong consumption externalities, firms obtain higher profits in the equilibrium under strategic managerial delegation compared with that under no-delegation. Here, we obtain a similar outcome but in a different framework. In particular,

\footnotetext{
${ }^{1}$ Duopoly models usually refer to the short-run. Hence, whenever there exists a fixed production factor, increasing costs should be the rule rather than the exception at a firm level (however, technologies may also exist, for example with a single factor, showing constant returns to scale and thus linear cost functions even in the short-run). Moreover, the existence of a convex cost function would have the effect to set a limit to the firms' size and to tend to break-up large firms, for instance, through a divisionalization, so that management may work on a more specific core business. Just to mention few examples, the break-up of the chemicals firm ICI into ICI and Zeneca in 1993 can be interpreted as a consequence of convex costs (Graham and Metha 2006, p.60) and, as regards financial sectors, Hanweck and Hogan (1996), using data from 1981-1985 for the U.S. property/casualty insurance industry, conclude that large firms are characterized by increasing (marginal) costs.
} 
the mechanism that drives our result hinges on the cost structure faced by firms and it is very different with respect to that played by network externalities. ${ }^{2}$ Hoernig (2012) also studies the effects of network externalities on managerial delegation highlighting that the choice of strategic delegation does not only depend on whether managers' strategic variables are quantities or prices, as is commonly asserted. In the same spirit, this paper shows that the equilibrium outcomes in a strategic delegation game can be actually affected by factors, namely asymmetric and convex costs, which are unrelated with the mode of competition. The relationship between managerial delegation and firms' asymmetric costs is considered in detail by van Witteloostuijn (1998) to explain differences in organizational decline (or exit rates) across firms. However, while in van Witteloostuijn (1998) the managerial delegation choice is exogenous, this paper studies how alternative delegation strategies interact with cost asymmetries (and convexity) in affecting firms' relative profitability, which also permits their delegation choice to be endogenously derived.

\section{$2 \quad$ Model}

We study a standard managerial duopoly market with convex cost functions. The generic firm $i$ produces a level of output $q_{i}$ with a total cost of:

$$
C_{i}\left(q_{i}\right)=w_{i} q_{i}+q_{i}^{2},
$$

so that the resulting marginal cost function is (linearly) increasing with an intercept of $w_{i} \geq 0$ that can differ between firms for the reasons mentioned in the Introduction.

The cost function given by (1) can be rationalized along different possible lines. First, it parallels that in Perry and Porter (1985), who consider that output is produced by combining a variable input (e.g. labor) with a fixed production factor. In such a case, the marginal cost function of any single firm is increasing due to the presence of the fixed factor of production: when firms increase labor to expand output, the fraction of the fixed factor used by each worker decreases. Hence labor (marginal) productivity decreases and the production cost increases at an increasing

\footnotetext{
2 From a mathematical point of view, the network consumption externalities and the convex (quadratic) costs assumptions are formally very different. In fact, in a model with network externalities, a firm's production enters the profit function of both firms in a positive and linear way while, conversely, in a negative and quadratic way in the model analyzed in this work.
} 
rate (specifically, the quadratic formulation allows for the achievement of analytical results). ${ }^{3}$ Alternatively, an analogous cost function is adopted by Mukherjee (2007), where the convex cost component is explained with the presence of organizational costs related to administrative, organizational and managerial consulting activities. Also note that this explanation can be considered, in some sense, a special case of the previous one based on the presence of a fixed factor, if we consider the latter as the firm's organization or management. Indeed, the manager's "span of control" increases with employment, which can make supervision inside the firm softer, leading to an increasing marginal cost of production. Finally, in a completely different way, van Long and Soubeyran (1998) obtain a similar expression for a firm's cost function in a model with heterogeneous workers who differ in their effort cost to providing one unit of output under two alternative wage regimes. In both regimes, the (endogenously) resulting firm's cost functions are very similar to that adopted here and (even if production technology is linear) are convex with respect to output, due to the particular mechanisms according to which wages are determined.

Firms compete à la Cournot for a single homogeneous product, with inverse demand given by $p=a-Q$, where $p$ denotes price and $Q$ is the sum of the firms' output $q_{i}$ and $q_{j}$, with $i, j=1,2$ and $i \neq j$. The owners of both firms may, or may not, hire a manager and delegate the output decision to this manager. Each manager receives a fixed salary plus a bonus element, which is related to a weighted combination between firms' profits and sales (output). More specifically, following Jansen et al. (2007, 2009) and van Witteloostuijn et al. (2007), if firm $i$ 's profits $\pi_{i}$ are positive - otherwise there is no bonus - manager $i$ receives a bonus that is proportional to $u_{i}=\pi_{i}+b_{i} q_{i}$, where the weight $b_{i}$ is chosen by owner $i$ to maximize profits. ${ }^{4}$ Accordingly, we explore a three-stage duopoly game where, at the first stage, each firm's owner chooses to delegate

\footnotetext{
${ }^{3}$ We defer to Perry and Porter (1985, pp. 220-221) for greater details (see also Heywood and McGinty 2007). Also note that according to this scenario, the total cost $C_{i}$ should include a (fixed) cost of the fixed factor, that is $C_{i}=f+w_{i} q_{i}+q_{i}^{2}$. Since entry decisions are not considered in this work, we can assume $f=0$ with no loss of generality.

${ }^{4}$ We also follow the standard assumption by managerial delegation theory that the fixed component (salary) of the manager's pay is chosen by the firm's owner such that the manager gets exactly his/her opportunity cost, which is normalized to zero. Also note that we concentrate on a sales delegation scheme à la Fershtman-Judd-Sklivas-Vickers, which represents the cornerstone model in the delegation game literature. However, also alternative schemes have been investigated by this literature, such as relative performance (Miller and Pazgal 2002) and, more recently, market share (Jansen et al. 2007). While we have to leave the final answers to further research, preliminary analyses suggest that our qualitative result holds true also under relative performance delegation.
} 
(or not) an output decision to a manager; at the second stage (when delegation has been chosen) the owner sets the incentive contract for the manager; finally, at the third stage, the firm's output is determined. As usual, we proceed with the analysis according to the backward logic.

When both firms decide, at the first stage, to delegate output decisions to the managers, standard analysis leads to the following firm $i$ 's equilibrium output, for given $w_{i}, w_{j}, b_{i}$ and $b_{j}$ :

$$
q_{i}\left(w_{i}, w_{j}, b_{i}, b_{j}\right)=\frac{3 a-4 w_{i}+w_{j}+4 b_{i}-b_{j}}{15},
$$

At the second stage, firms' owners choose the bonus weights to maximize profits, leading to:

$$
b_{i}\left(b_{j}\right)=\frac{3 a-w_{i}+w_{j}-b_{j}}{56}
$$

which, in turn, leads to the following (asymmetric) equilibrium values:

$$
\begin{aligned}
b_{i}^{D / D} & =\frac{11 a-15 w_{i}+4 w_{j}}{209} ; \quad q_{i}^{D / D}=\frac{4\left(11 a-15 w_{i}+4 w_{j}\right)}{209} ; \\
\pi_{i}^{D / D} & =\frac{28\left[121 a^{2}-22 a\left(15 w_{i}-4 w_{j}\right)+225 w_{i}^{2}+16 w_{j}^{2}-120 w_{i} w_{j}\right]}{43681} .
\end{aligned}
$$

According to the previous results, although both owners always give incentives for sales, the bonus weight set by the more efficient firm's owner is higher than that fixed by his/her rival. Indeed, from $b_{i}^{D / D}$ in (4) (and its counterpart for $b_{j}{ }^{D / D}$ ), it follows that $b_{i}^{D / D}>b_{j}{ }^{D / D} \Leftrightarrow w_{i}<w_{j}{ }^{5}$

We consider now the case in which both firms choose not to delegate the output decision to managers. The analysis straightforwardly parallels that of the above section with $b_{i}=b_{j}=0$ and equilibrium results concerning output and profits are:

$$
q_{i}^{N D / N D}\left(w_{i}, w_{j}\right)=\frac{3 a-4 w_{i}+w_{j}}{15} ; \quad \pi_{i}^{N D / N D}=\frac{2\left(3 a-4 w_{i}+w_{j}\right)^{2}}{225} .
$$

\footnotetext{
${ }^{5}$ An analogous result is obtained, for instance in Fershtman and Judd (1987), with linear costs. Note that a negative bonus weight $b_{i}$ being negative (i.e., the firm $i$ 's owner "penalizes" sales) would imply $w_{i}>\left(11 a+4 w_{j}\right) / 15$ but, according to (10), this is at odds with the condition for non-negative output.
} 


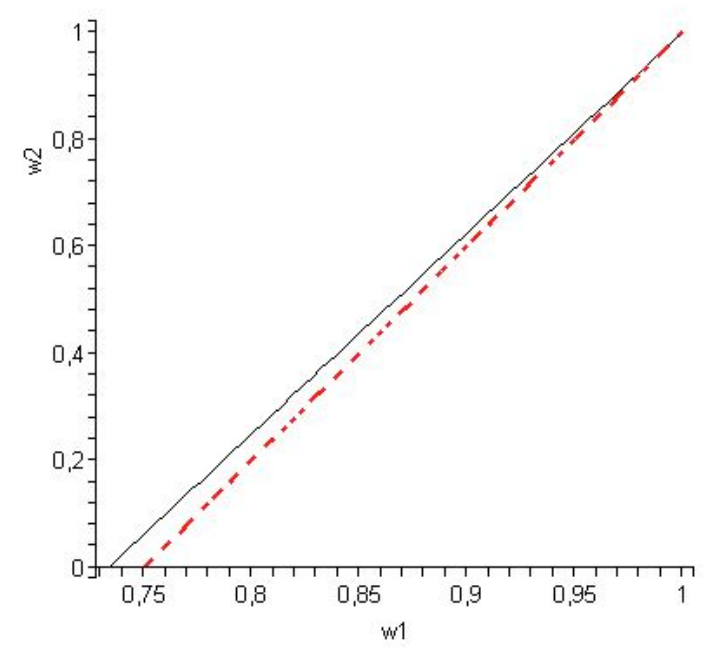

Figure 1: Plot of the "threshold curves" $O_{1, D}$ and $O_{1, N D}$ in $\left[w_{1}, w_{2}\right]$-space $[a=1]$

Finally, the "feasibility" of the economic models presented above ultimately requires the non-negativity condition for each firm's output. Figure 1 shows the combination of cost parameters that allow a "feasible" economic model (i.e., non-negative quantity of firm 1 when its cost $w_{1}$ varies for any given cost $w_{2}$ of the rival firm). In particular, by defining $O_{1, D}\left(w_{1}, w_{2}\right):=q_{1}^{D / D}=0$ and $O_{1, N D}\left(w_{1}, w_{2}\right):=q_{1}^{N D / N D}=0$, they are displayed in Fig. 1 (the curves $O_{l, D}$-black solid line- and $O_{l, N D}$ -red dotted line- are drawn for $a=1)$ : for all pairs $\left(w_{1}, w_{2}\right)$ above (below) each curve, the equilibrium output of firm 1 is positive (negative), that is, $O_{1, D}>(<) 0$ and $O_{1, N D}>(<) 0$.

\subsection{Asymmetric strategies: managerial delegating firm vs. profit-maximizing firm}

In order to derive the endogenous choice by firms' owners on managerial delegation, we now have to analyze what happens when firm $i$ chooses to delegate the output decision to a manager, while the other firm $j$ adopts the different strategy (i.e., profit maximization). In such a case, we get that at the final stage the firm's $i$ output is given by:

$$
q_{i}\left(w_{i}, w_{j}, b_{i}\right)=\frac{3 a-4 w_{i}+w_{j}+4 b_{i}}{15},
$$

which leads to the following equilibrium values: 


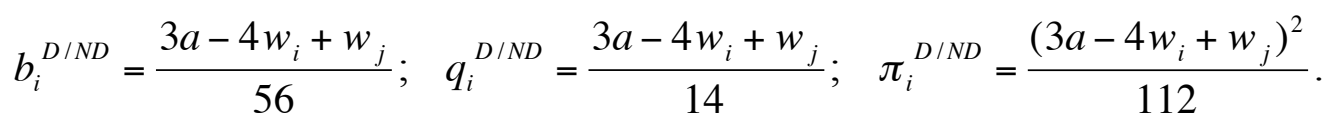

It is confirmed that it is optimal for the "delegating" firm to provide incentives for sales (otherwise output would be negative) and that the bonus weight is higher when the delegating firm is more efficient than its rival. Finally, a similar procedure for the (profit-maximizing) firm $j$ (when firm $i$ chooses to delegate) yields to the following equilibrium outcomes:

$$
q_{j}^{D / N D}=\frac{11 a+4 w_{j}-15 w_{i}}{56} ; \quad \pi_{j}^{D / N D}=\frac{\left(11 a+4 w_{j}-15 w_{i}\right)^{2}}{1568}{ }^{6}
$$

\section{Strategic endogenous choice and managerial delegation profitability}

In the first stage, firms' owners simultaneously choose whether or not to delegate the output decision.

\begin{tabular}{|c|c|c|}
\hline firm $i /$ firm $j$ & $N D$ & $D$ \\
\hline$N D$ & $\frac{2\left(3 a-4 w_{i}+w_{j}\right)^{2}}{225}, \frac{2\left(3 a+w_{i}-4 w_{j}\right)^{2}}{225}$ & $\frac{\left(11 a-15 w_{i}+4 w_{j}\right)^{2}}{1568}, \frac{\left(3 a-4 w_{i}+w_{j}\right)^{2}}{112}$ \\
\hline$D$ & $\frac{\left(3 a-4 w_{i}+w_{j}\right)^{2}}{112}, \frac{\left(11 a-15 w_{i}+4 w_{j}\right)^{2}}{1568}$ & $\frac{28\left[121 a^{2}-22 a\left(15 w_{i}-4 w_{j}\right)+225 w_{i}{ }^{2}+16 w_{j}{ }^{2}-120 w_{i} w_{j}\right]}{43681}$, \\
& & $\frac{28\left[121 a^{2}+22 a\left(-15 w_{j}+4 w_{i}\right)+16 w_{i}{ }^{2}+225 w_{j}{ }^{2}-120 w_{i} w_{j}\right]}{43681}$, \\
\hline
\end{tabular}

Table 1: Stage 1 game: strategic form

\footnotetext{
${ }^{6}$ It is worth noting that those results extend to the quadratic cost function of this model the well-known Basu's (1995) explanation (with linear costs) of Stackelberg leadership in product markets based on managerial delegation. Indeed, also in the subgame-perfect equilibrium of this model, quantities and profits for, respectively, the firm that rewards on the basis of a weighted profits and sales scheme and for that rewarding on the basis of pure profits only are the same of the Stackelberg duopoly (the proof is straightforward and it is omitted for economy of space; we are grateful to an anonymous referee for having highlighted this point).
} 
Table 1 shows the strategic form of the first-stage game, where $N D$ refers to the "nodelegation" (or "profit maximization") strategy while $D$ to that consisting of delegating the output decision to the manager. Firstly, note that, in the "asymmetric strategies" case, firm $i$ (which is assumed to delegate the strategic decision to the manager) is always willing to deviate unilaterally from profit maximization:

$$
\pi_{i}^{D / N D}-\pi_{i}^{N D / N D}=\frac{\left(3 a-4 w_{i}+w_{j}\right)^{2}}{25200}>0
$$

Moreover, firm $i$ 's pay-off under $D / D$ strategies is always larger than under $N D / D$ strategies:

$$
\pi_{i}^{D / D}-\pi_{i}^{N D / D}=\frac{223\left[121 a^{2}-22 a\left(15 w_{i}-4 w_{j}\right)+225 w_{i}^{2}+16 w_{j}^{2}-120 w_{i} w_{j}\right]}{68491808}>0 .
$$

Accordingly, each owner unilaterally allows for managerial delegation. Hence managerial delegation of both firms is the SPNE of the game. However, the conventional (Prisoner's Dilemma) outcome that both firms are better off under $N D / N D$ strategies does not hold if the cost parameters are sufficiently differentiated.

Lemma. For a given $w_{j}$, if $w_{i}<\bar{w}_{i}\left(<w_{j}\right)$, firm $i$ is better off under D/D strategies than ND/ND strategies. Instead, if $w_{i}>\overline{\bar{w}}_{i}\left(>w_{j}\right)$, firm $j$ is better off under D/D strategies than ND/ND strategies.

Proof: Taking profits from (4) and (5) into account, we obtain:

$$
\pi_{i}^{D / D}-\pi_{i}^{N D / N D}=-\frac{2\left[11979 a^{2}-66 a\left(134 w_{i}+229 w_{j}\right)-9854 w_{i}{ }^{2}-6719 w_{j}{ }^{2}+28552 w_{i} w_{j}\right]}{9828225},
$$

from which it may be deduced that:

$$
\begin{aligned}
& \pi_{i}^{D / D}-\pi_{i}^{N D / N D}>0 \Leftarrow w_{i}<\bar{w}_{i}=2.639 w_{j}-1.639 a \\
& \pi_{j}{ }^{D / D}-\pi_{j}^{N D / N D}>0 \Leftarrow w_{i}>\overline{\bar{w}}_{i}=0.258 w_{j}+0.742 a
\end{aligned}
$$


Proposition. According to Table 1, the SPNE of the managerial delegation game between owners is $(D / D)$. However, when $w_{i}$ and $w_{j}$ are sufficiently different, in equilibrium, the more efficient firm obtains a higher profit than under (ND/ND). This implies that, in such a case, the managerial delegation game does not represent a Prisoner's Dilemma type of situation and the profitmaximization strategy is no longer Pareto-improving from the viewpoint of the firms' owners.

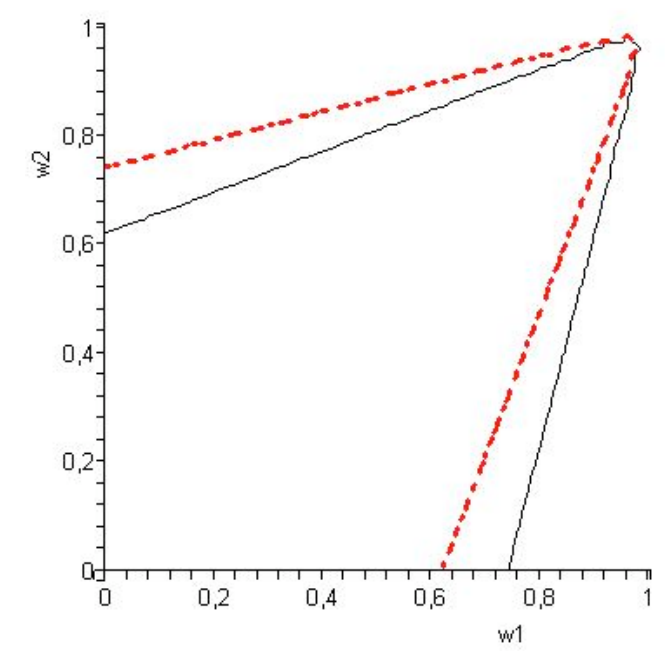

Figure 2: Plot of the "threshold curves" $F_{1}$ and $F_{2}$ in $\left[w_{1}, w_{2}\right]$-space $[a=1]$

Let define $F_{1}\left(w_{1}, w_{2}\right):=\left(\pi_{1}^{D / D}-\pi_{1}^{N D / N D}\right)=0$ and $F_{2}\left(w_{1}, w_{2}\right):=\left(\pi_{2}^{D / D}-\pi_{2}^{N D / N D}\right)=0$. In Figure 2, the curves $F_{1}$ (black solid line) and $F_{2}$ (red dotted line) show all $\left(w_{1}, w_{2}\right)$ combinations for which $F_{1}=F_{2}=0$ holds true. More specifically, for all $\left(w_{1}, w_{2}\right)$ combinations below (above) each curve, the equilibrium profit of firm 1 is higher (lower) under profit maximization (no-delegation) than under delegation, that is, $F_{1}>(<) 0$ and $F_{2}>(<) 0$. The joint observation of Figures 1 and 2 exhaustively provides all the "feasible" parametric regions in terms of costs, for which the results established above apply. A simple example can also be useful to provide a further illustration of them. We fix, for simplicity, $a=1$ and $w_{2}=0.66$. Then, first we find the conditions for the nonnegativity of $q_{1}$ in both strategies; see also Fig. 1 (obviously $q_{2}$ is always non-negative for any value of $\left.w_{1}\right)$ :

$q_{1}^{D / D} \geq 0 \Leftarrow w_{1} \leq 0.909 ; q_{1}^{N D / N D} \geq 0 \Leftarrow w_{1} \leq 0.915$

Secondly, from the Lemma, we obtain $\bar{w}_{1}=0.103$ and $\overline{\bar{w}}_{1}=0.871$ (see Fig. 2). Moreover: 
$\pi_{1}^{D / D}-\pi_{1}^{N D / N D}>0 \Leftarrow w_{1}<\bar{w}_{1} ; \pi_{2}^{D / D}-\pi_{2}^{N D / N D}>0 \Leftarrow w_{1}>\overline{\bar{w}}_{1}$.

Therefore, at a given $w_{2}=0.66$, the conventional wisdom is reverted either when the cost parameter of firm 1 lies between 0 and 0.103 (i.e., firm 1 is better off under $D / D$ than under $N D / N D$ ) or between 0.871 and 0.909 (i.e., firm 2 is better off under $D / D$ than under $N D / N D$ ).

\section{Conclusion}

In this paper we reconsidered the problem of managerial delegation and sales (output) incentives in the presence of asymmetric and convex costs faced by firms. This is important for the IO literature since it permits to shed new light on the role of the cost structure by firms in affecting the strategic delegation choice, which is a key issue for management strategy.. Relative to the received literature, our findings can be summarized as follows: even if managerial delegation still represents a SPNE of the game, the more efficient firm may obtain a larger profit than in a situation in which both firms do not delegate, which means that "no-delegation" is no longer Pareto-improving (from the firms' viewpoint).

Future research dealing with the main limitations of this work and aiming to extend it could be carried out along possible different lines. Just to mention a few, even if we broadly motivated, referring to the received literature, the relevance of the key features (asymmetry between firms and convexity) of the firm's cost function adopted herein, the choice of such a function was exogenous. Obviously, making the firms' cost functions endogenous could add further value to our results. Secondly, while we only concentrated on Cournot competition, it is important to analyze also a managerial delegation model with firms that compete in prices. Moreover, the robustness of our results could be checked by extending the model with the introduction of other types of managerial delegation contracts (e.g., "relative profit delegation" or "market share delegation") or considering a situation in which the bonus weights are bargained between firms and managers.

\section{References}

Baden-Fuller CWF. 1989. Exit from declining industries and the case of steel castings. Economic Journal 99: 949-961. 
Basu K. 1995. Stackelberg equilibrium in oligopoly: an explanation based on managerial incentives. Economics Letters 49: 459-464.

Bhattacharjee T, Pal R. 2013. Network externalities and strategic managerial delegation in Cournot duopoly: is there a prisoners' dilemma? Review of Network Economics 12: 343-353.

Dawson G. and J. Metha, 2006, Innovation, markets and industrial change, in Dawson, G., Mackintosh M., and P., Anand (eds.), Economics and Economic Change. Microeconomics, The Open University, Milton Keynes, UK, pp. 44-74.

Fershtman C. 1985. Managerial incentives as a strategic variable in duopolistic environment. International Journal of Industrial Organization 3: 245-253.

Fershtman C, Judd K. 1987. Equilibrium incentives in oligopoly. American Economic Review 77: 927-940.

Frank MZ. 1988. An intertemporal model of industrial exit. Quarterly Journal of Economics 103: $333-344$.

Ghemawat P, Nalebuff B. 1985. Exit. RAND Journal of Economics 16: 184-194.

Hanweck, G. A. and A. B. Hogan, 1996, "The Structure of the Property/Casualty Insurance Industry," Journal of Economics and Business 48: 141-155.

Heywood JS, McGinty M. 2007. Convex costs and the merger paradox revisited. Economic Inquiry 45: $342-349$.

Hoernig S. 2012. Strategic delegation under price competition and network effects. Economics Letters 117: 487-489.

Holmes TJ, Schmitz Jr. JA. 1995. On the turnover of business firms and business managers. Journal of Political Economy 103: 1005-1038.

Jansen T, van Lier A, van Witteloostuijn A. 2007. A note on strategic delegation: the market share case. International Journal of Industrial Organization 25: 531-539.

Jansen T, van Lier A, van Witteloostuijn A. 2009. On the impact of managerial bonus systems on firm profit and market competition: the cases of pure profit, sales, market share and relative profits compared. Managerial and Decision Economics 30: 141-153. 
Jovanovic B, Lach S. 1989. Entry, exit, and diffusion with learning by doing. American Economic Review 79: 690-699.

Jovanovic B, McDonald GM. 1994. The life cycle of a competitive industry. Journal of Political Economy 102: 322-347.

Miller N, Pazgal A. 2002. Relative performance as a strategic commitment mechanism. Managerial and Decision Economics 23: 51-68.

Mukherjee A. 2007. Irrelevance of productivity difference: a case with labor union. Economics Bulletin 10: 1-8.

Perry M, Porter RH. 1985. Oligopoly and incentive for horizontal merger. American Economic Review 75: 219-227.

Shapiro C, Stiglitz J. 1984. Equilibrium unemployment as a worker discipline device. American Economic Review 74: 433-444

Sklivas S. 1987. The strategic choice of managerial incentives. RAND Journal of Economics 18: $452-458$.

van Long N, Soubeyran A. 1998. Oligopolistic trade and competition in wage legislations. Japanese Economic Review 49: 158-170.

Vickers J. 1985. Delegation and the theory of the firm. Economic Journal 95: 138-147.

van Witteloostuijn A. 1998. Bridging behavioral and economic theories of decline: organizational inertia, strategic competition, and chronic failure. Management Science 44: 501-519

van Witteloostuijn A, Jansen T, van Lier A. 2007. Bargaining over managerial contracts in delegation games: managerial power, contract disclosure and cartel behavior. Managerial and Decision Economics 28: 897-904.

White MD. 1996. Mixed oligopoly, privatization and subsidization. Economics Letters 53: 189-195. 